\title{
EDITORIAL
}

\section{Marine Ecology Progress Series (MEPS) celebrates its 600th volume: maintaining top quality in rapidly changing times}

\author{
Myron A. Peck ${ }^{1, *}$, Katherine Richardson ${ }^{2}$, Paul Snelgrove ${ }^{3}$, Rory Wilson ${ }^{4}$ \\ ${ }^{1}$ Center for Earth Systems Research and Sustainability (CEN), University of Hamburg, 22767 Hamburg, Germany \\ ${ }^{2}$ Department of Biology, Ecology and Evolution, University of Copenhagen, 2100 Copenhagen, Denmark \\ ${ }^{3}$ Canada Research Chair in Boreal \& Cold Ocean Systems, Ocean Sciences Centre, Memorial University of Newfoundland, \\ St. John's, NL A1C 5S7, Canada \\ ${ }^{4}$ Biosciences, College of Science, Swansea University, Swansea, SA2 8PP, UK
}

The Editors-in-Chief take this opportunity to proudly celebrate together with the editorial team the 600th volume of MEPS. Since its founding in 1979, MEPS has changed considerably, as has scientific publishing in general. Here, we offer a few brief comments and consider recent trends as we look back at MEPS's continued success and look ahead at our bright future.

In 1979, rapid advancements in the field of marine ecology led Prof. Otto Kinne to found MEPS and its publisher Inter-Research. Prof. Kinne continued to lead MEPS up to his death at the age of 91 in the spring of 2015. Prof. Kinne's legacy and stewardship of MEPS is being continued by the dedicated staff at Inter-Research and the new editorial leadership of 4 Editors-in-Chief. This team has helped maintain this journal as a premiere venue for marine ecological research. Over the last 5 years, the journal has published 23 volumes per year, often with 275 to 300 pages per volume. Despite this high throughput, MEPS's top priority remains publication of only the highest quality science that advances knowledge on processes within the broad field of marine ecology from microbes to whales, from shallow water coasts to the ocean's abyssal depths.

Scientists tackling questions in marine ecology now face a bewildering selection of potential publication outlets with the creation of an endless number of new journals during the last decade. In some ways, MEPS has become a positive outlier in this new

\footnotetext{
*Email: myron.peck@uni-hamburg.de
}

publishing landscape. MEPS continues to focus on quality over quantity. Authors are provided with thorough, critical yet constructive reviews of their work (our average is 2.9 reviews per manuscript) as well as thorough copy-editing during production both factors leading to a high-quality publication. Our personal approach when communicating and working with authors also defines the 'MEPS experience'. We at MEPS will maintain these traditions because we think they are the hallmark to providing the best publishing experience for authors and top science to readers.

The increasing variety of outlets now available to scientists for communicating their work and the new ways in which the success of a scientist is judged constitute other important, recent developments. While it is true that the traditional methods of judging scientific merit, publication of peer-reviewed articles (as a permanent testament to the quality of science being undertaken by the authors) and oral presentations are important, more ephemeral communication outlets continue to grow. In this age of rapid information transfer, LinkedIn, Twitter and Facebook amongst others are playing an ever-increasing role in science communication. These outlets reach scientists, the public and policy-makers fast; so fast, in fact, that they have become a mainstay for flash news, especially for early career researchers. The role of social media as a tool to assess a scientist's merit will likely continue to increase.

() The authors 2018. Open Access under Creative Commons by Attribution Licence. Use, distribution and reproduction are unrestricted. Authors and original publication must be credited. 
MEPS has adapted and will continue to change to keep pace with the new realities of science communication. Efforts to help authors increase their online footprint began in earnest in September 2016 with the establishment of MEPS's Facebook and Twitter accounts. We invite authors of recently accepted articles to supply photos and short statements for posting on these sites. Our number of new likes, new posts, new followers and new tweets is growing exponentially. Follow our latest content on our Facebook (www.facebook.com/MarEcolProgSer) and Twitter (www.twitter.com/MEPS_IR) websites to stay at the forefront of marine ecology.

Since the first volume of MEPS appeared in 1979, the field of marine ecology has come into its own and continues to change rapidly. In connection with its 40th anniversary next year, MEPS will invite editorials from some of our field's leading researchers to chronicle changes in specific fields and developments through the previous 4 decades. The molecular genomics revolution, new remotesensing capabilities, new digital imaging capacity, expanding computation and modeling capacity, and developments in macro-ecology offer the promise of major advances in marine ecology in the coming years. Contributing Editors working in emerging areas will continue to be added to our strong board so that the collective expertise of this group keeps pace with the latest developments in marine ecology.

With so many changes happening in marine ecology and in science communication, this is a particularly exciting time to be at the helm of MEPS. While we will continually expand to maintain complete coverage of the field and to meet the needs of today's science communication landscape, the Editors-inChief and in-house editors will never jeopardize the core values that make MEPS the premier journal in marine ecology. Those values encompass quality both in the science itself and in its presentation.

Last, but certainly not least, the Editors-in-Chief express their sincere appreciation to the authors, reviewers and editors for their hard work and dedication (and top-notch science). Without you, MEPS would not be the premier journal that it is today. A heartfelt 'thank you'! 